\title{
Store Atmospherics: An Abstract
}

\author{
Charles Spence
}

\begin{abstract}
In a multisensory perspective, there can be little doubting that the multisensory atmospherics in stores and other commercial spaces affect the behavior of consumers in systematic ways (see Spence 2018a; Spence et al. 2014, for reviews). This message has created a revolution in sensory marketing, such that across virtually every product category, retailers (and manufacturers) are now increasingly seeking to influence the "sensory experience" of their consumers. One of the key questions then becomes how should a company design its multisensory atmospherics in store to ensure that the return on investment is worthwhile? And what is the relevant metric, anyway? Increased sales, or column inches in the press? But lurking in the background is also an ethical question around whether the effective design of multisensory atmospherics may be pushing more of us into consuming more than we otherwise might (see Spence 2015, 2018b, for reviews). In this talk, I will review the consumer scientific evidence related to visual, auditory, tactile, olfactory, and even gustatory aspects of the store environment and their influence on the consumer's behavior. I will highlight a number of areas where further research is needed in order to better understand how the multisensory retail environment shapes customer experience and shopping behavior. I will also discuss the latest findings in terms of the currently accepted cognitive neuroscience models of multisensory perception. Should there be time, I would also like to briefly address the question of whether there are meaningful individual/cultural differences in the desire for/avoidance of overly stimulating environments among consumers. Finally, I will take a look at how new technologies are changing the multisensory landscape for consumers.
\end{abstract}

References Available Upon Request

C. Spence $(\bowtie)$

University of Oxford, Oxford, UK

e-mail: charles.spence@psy.ox.ac.uk 